\title{
Long-term home care programmes may reduce hospital admissions in COPD with chronic hypercapnia
}

\author{
E. Clini, M. Vitacca, K. Foglio, P. Simoni, N. Ambrosino
}

\begin{abstract}
Long-term home care programmes may reduce hospital admissions in COPD with chronic hypercapnia. E. Clini, M. Vitacca, K. Foglio, P. Simoni, N. Ambrosino. CERS Journals Ltd 1996.

ABSTRACT: Long-term oxygen therapy (LTOT) has been shown to improve survival in chronic obstructive pulmonary disease (COPD) patients. The clinical effectiveness of long-term home mechanical ventilation (HMV) is still discussed, nevertheless both LTOT and HMV are often included in the home care programmes of these patients.

To evaluate the effectiveness of home care programmes including either HMV or LTOT, 34 COPD patients were studied. They were admitted to either HMV (Group A: 12 males and 5 females, aged 62 \pm 5 yrs), or LTOT (Group B: 9 males and 8 females, aged $62 \pm 8 \mathrm{yrs}$ ). They were compared to a historical group (Group C: 19 males and 10 females, aged $67 \pm 16$ yrs) performing only their usual standard LTOT during the same period. Spirometry, maximal inspiratory pressure and arterial blood gas values were assessed at baseline and at 6, 12 and 18 months of followup. Mortality rate and number of hospital and intensive care unit (ICU) admissions and days of hospitalization were also assessed.

Four out of $17(23 \%)$ patients in Group A, 3 out of $17(18 \%)$ in Group B, and 5 out of $29(17 \%)$ in Group $C$ died within 18 months. Of the lung function tests, only maximal inspiratory pressure in Group A showed a significant increase in the 18th month $\left(50 \pm 4\right.$ to $\left.56 \pm 7 \mathrm{cmH}_{2} \mathrm{O} ; \mathrm{p}<0.01\right)$. In comparison to 18 months prior to the study, hospital admissions (from $2.2 \pm 0.6$ to $1.3 \pm 1.1$ and from $2.0 \pm 0.7$ to $1.0 \pm 0.9$ for Group $A$ and B, respectively; $\mathbf{p}<\mathbf{0 . 0 0 5}$ for both), and days of hospitalization (from $60 \pm 34$ to $34 \pm 40$ and from $55 \pm 23$ to $18 \pm 20$ days in Group $A$ and $B$, respectively; $\mathbf{p}<\mathbf{0 . 0 0 5}$ for both) significantly decreased only in the two groups submitted to the home care programme.

We conclude that home care programmes may be effective in the long-term treatment of chronically hypercapnic chronic obstructive pulmonary disease patients in reducing hospital admissions.

Eur Respir J., 1996, 9, 1605-1610.
\end{abstract}

Salvatore Maugeri, Clinica del Lavoro Foundation IRCCS, Divisions of Pneumology, Medical Centers of Gussago (BS), Italy.

Correspondence: E. Clini

Clinica del Lavoro Foundation IRCCS

Via Pinidolo 23

25064 Gussago (BS)

Italy

\section{Keywords:}

Chronic obstructive pulmonary disease

home care

home mechanical ventilation

long-term oxygen

Received: September 301994

Accepted after revision April 241996
Long-term oxygen therapy (LTOT) has been shown to improve survival in chronic obstructive pulmonary disease (COPD) [1, 2]. Long-term mechanical ventilation through tracheostomy is performed in ventilator-dependent patients with chronic respiratory insufficiency from restrictive and obstructive diseases [3]. Although several studies have reported a favourable effect on daytime gas exchange using nocturnal noninvasive home mechanical ventilation (HMV) in restrictive pulmonary diseases [4-8], the long-term effectiveness of such a modality in COPD is still discussed and only uncontrolled trials have been performed [9-11].

Recently, hospital-based home care programmes have been proposed in the long-term treatment of COPD patients with chronic respiratory insufficiency, with the aim of improving quality of life and reducing hospitalization and cost/benefit ratio, but few data from studies in this field are available [12-16]. Furthermore, few data are available on the relative role of HMV and LTOT in home care programmes.
The aim of this study was, therefore, to assess the effectiveness of a new home care programme including, either long-term HMV added to LTOT, or LTOT alone in chronically hypercapnic COPD patients.

\section{Methods}

\section{Patients}

We studied 34 patients with severe COPD as defined by American Thoracic Society (ATS) criteria [17], who were recruited from December 1991 to September 1992 by our department and proposed for a controlled pros pective study evaluating the effectiveness of home care programmes including either HMV and LTOT, or LTOT alone. All the patients met the criteria for LTOT [18] and had been on LTOT for at least 18 months. Inclusion criteria were: 1) chronic hypercapnia (arterial carbon 
dioxide tension $\left.\left(\mathrm{Pa}_{\mathrm{a}} \mathrm{CO}_{2}\right)>6.7 \mathrm{kPa}(50 \mathrm{mmHg})\right)$; 2) at least one hospital admission due to severe exacerbation in the preceding 18 months; 3) willingness to participate in a home care programme; 4) evidence of family support or availability of a care-giver; and 5) geographic location allowing easy reach.

Patients were excluded if they had: a $15 \%$ or greater increase in forced expiratory volume in one second (FEV1) after administration of an inhaled bronchodilator; suspicion of sleep apnoea as assessed by arterial saturation monitoring [19]; and co-existing medical conditions, such as uncontrolled coronary heart disease, malignancies or any other condition that could make them unsuitable to be included in long-term trials.

Patients were divided into two groups matched for anthropometric, functional and blood gas data: Group A (12 males and 5 females, aged $62 \pm 5$ yrs) was included in a home care programme involving HMV and LTOT; Group B (9 males and 8 females, aged $67 \pm 7$ yrs) was submitted to a home care programme carrying out LTOT alone.

Inclusion in the two groups was not random. Patients included in Group A followed the above criteria and had suffered from at least one episode of acute respiratory failure (ARF) needing noninvasive mechanical ventilation (NMV) [20] (11 patients) or had undergone at least two admissions to respiratory units for severe exacerbations not requiring ventilatory support in the previous 18 months (6 patients).

Seven of the 17 patients included in Group B had undergone intensive care unit (ICU) admissions needing mechanical ventilation but were not able to perform long-term HMV.

These two groups were compared with a historical control group of COPD patients (Group C) performing only LTOT (19 males and 10 females, aged $62 \pm 8$ yrs), retrospectively selected from our department, and comparable in terms of anthropometric data and severity of underlying illness. They had performed LTOT for at least 18 months prior to the beginning of observation, and were followed up for a further 18 months in the same periods as Group A and B.

Throughout the study, all patients continued their standard medical therapy, including theophylline, steroids and bronchodilators. Changes in medical therapy, when needed, were prescribed by physicians in our department or by the general practitioner who was not involved in the study.

Informed consent was obtained from all the patients of Group A and B at the beginning of the study, which was approved by the Ethics Committee of Salvatore Maugeri Foundation.

\section{Home supervision programme}

The home care programme consisted of a supervision programme planned during an in-hospital preliminary evaluation and included physical, occupational and dietary information, with a special trial for the families. After discharge, the programme was co-ordinated by our department and aimed to provide a link service between the hospital and the community health service by means of telephone contact with general practitioners and patients.
Home supervision was also ensured by a physician from our department by means of monthly visits, in which physical examination, functional status (assessment of spirometry, inspiratory muscle (IM) function, arterial blood gas (ABG) values), and correct performance of treatment was assessed. The visiting physician also gave the patients and family members a better insight into the possible disabilities and handicaps due to impairment of the lungs. Information was given about pulmonary disease, various strategies of treatment, how to use medication, how the patient could cope with the disease and the role of their specific treatment [21]. Control of equipment was also performed. The staff physician made clinical decisions about hospitalization during the periodical domiciliary routine or emergency calls.

\section{Ventilatory assistance and long-term oxygen therapy}

Noninvasive mechanical ventilation was initiated during a preliminary hospital trial when patients were in a stable state and was administered via a standard nasal mask (Respironics Inc., Monroeville, PA, USA) using a bilevel positive airway pressure (BiPAP®) ventilator (Respironics Inc., Monroeville, PA, USA) [22, 23]. After correct mask fitting, the ventilatory device was set with the minimal inspiratory positive airway pressure (IPAP) able to achieve a expiratory tidal volume $(V \mathrm{~T})>8 \mathrm{~mL} \cdot \mathrm{kg}^{-1}$ (this value ranged $\left.10-16 \mathrm{cmH}_{2} \mathrm{O}\right)$. The expiratory positive airway pressure (EPAP) ranged $0-2 \mathrm{cmH}_{2} \mathrm{O}$. A back-up respiratory frequency of 10 breaths $\cdot \mathrm{min}^{-1}$ was also set. The in-hospital trial was prolonged for at least 15 days, and patients were instructed to perform adequate HMV at night for a minimum of $8 \mathrm{~h}$. The length of time patients used the ventilator was assessed by interviewing the patients and relatives and by controlling the device counter.

Patients of both groups continued LTOT as previously prescribed. Oxygen supplementation in Group A was also continued during HMV via a cannula attached to a port on the nasal mask, when necessary, to achieve an arterial oxygen tension $\left(\mathrm{Sa}_{\mathrm{a}} \mathrm{O}_{2}\right)>92 \%$. This value was also the target of LTOT.

\section{Lung function tests}

In all groups, baseline measurements of dynamic and static volumes were obtained from a body plethysmograph (1085 Medical Graphics, USA). In Group A and B, baseline and follow-up measurements of FEV1, forced vital capacity (FVC) and FEV1/FVC ratio were obtained using a portable spirometer (Pocket Monitor Micro Medical Ltd, Rochester, UK).

Monitoring of lung function and ABG values was performed at home (Groups A and B) or during ambulatory control (Group C) after 6, 12 and 18 months. Inspiratory muscle strength was evaluated only in Group A and B, by assessment of maximal inspiratory pressure (MIP) using a portable manometer (NIF Markos, Monza, Italy; range $0-150 \mathrm{cmH}_{2} \mathrm{O}$ ) during a maximal static inspiratory effort against an occluded airway from functional residual capacity (FRC) [24]. Predicted values were those of BRUSCHI et al. [25]. The best of five measurements was recorded. 
Table 1. - Baseline demographic, anthropometric and functional data of the COPD patients

\begin{tabular}{|c|c|c|c|c|}
\hline & $\begin{array}{c}\text { Group A } \\
(n=17)\end{array}$ & $\begin{array}{c}\text { Group B } \\
(n=17)\end{array}$ & $\begin{array}{c}\text { Group C } \\
(n=29)\end{array}$ & p-value* \\
\hline Age yrs & $62 \pm 5$ & $67 \pm 7$ & $62 \pm 8$ & NS \\
\hline Gender $\mathrm{M} / \mathrm{F}$ & $12 / 5$ & $9 / 8$ & $19 / 10$ & NS \\
\hline Weight $\mathrm{kg}$ & $67 \pm 11$ & $60 \pm 7$ & $63 \pm 20$ & NS \\
\hline Height $\mathrm{cm}$ & $167 \pm 6$ & $164 \pm 7$ & $162 \pm 8$ & NS \\
\hline \multicolumn{5}{|c|}{ Pulmonary function } \\
\hline FEV1 L & $0.8 \pm 0.3$ & $0.8 \pm 0.2$ & $0.8 \pm 0.3$ & NS \\
\hline FEV1 \% pred & $31 \pm 10$ & $33 \pm 10$ & $31 \pm 12$ & NS \\
\hline FVC \% pred & $51 \pm 12$ & $54 \pm 13$ & $51 \pm 14$ & NS \\
\hline FEV1/FVC \% & $50 \pm 18$ & $49 \pm 12$ & $50 \pm 18$ & NS \\
\hline TLC \% pred & $103 \pm 17$ & $108 \pm 10$ & $107 \pm 13$ & NS \\
\hline RV \% pred & $155 \pm 21$ & $141 \pm 22$ & $139 \pm 21$ & NS \\
\hline FRC \% pred & $115 \pm 19$ & $110 \pm 11$ & $114 \pm 21$ & NS \\
\hline $\mathrm{MIP} \mathrm{cmH}_{2} \mathrm{O}$ & $48 \pm 8$ & $50 \pm 4$ & NA & NS \\
\hline \multicolumn{5}{|c|}{ Arterial blood gas levels ${ }^{\#}$} \\
\hline$P \mathrm{a}, \mathrm{O}_{2} \mathrm{kPa}$ & $7.2 \pm 0.9$ & $6.6 \pm 0.6$ & $6.8 \pm 0.6$ & NS \\
\hline$P \mathrm{a}_{1} \mathrm{CO}_{2} \mathrm{kPa}$ & $6.4 \pm 1.4$ & $6.4 \pm 0.5$ & $6.7 \pm 0.6$ & NS \\
\hline $\mathrm{pH}$ & $7.38 \pm 0.03$ & $7.37 \pm 0.01$ & $7.38 \pm 0.03$ & NS \\
\hline
\end{tabular}

Values are presented as mean \pm SD. \#: breathing room air; *: by analysis of variance. Group A: included in home care programme involving home mechanical ventilation and long-term oxygen therapy (LTOT); Group B: included in home care programme involving LTOT only; Group C: historical control group performing only LTOT. COPD: chronic obstructive pulmonary disease; M: male; F: female; FEV1: forced expiratory volume in one second; FVC: forced vital capacity; \% pred: percentage of predicted value; TLC: total lung capacity; RV: residual volume; FRC: forced residual capacity; MIP: maximal inspiratory pressure; $\mathrm{P}_{\mathrm{a}, \mathrm{O}_{2}}$ : arterial oxygen tension; $P \mathrm{a}, \mathrm{CO}_{2}$ : arterial carbon dioxide tension; NA: not available; NS: nonsignificant.

ABG values were assessed at home (Group A and B) taking blood samples from the radial artery whilst breathing room air, cooling them at $0-4^{\circ} \mathrm{C}$ and sending them to the hospital to be analysed by means of an analyser (ABL 300 Radiometer, Copenaghen, Denmark) within $30 \mathrm{~min}$. The accuracy of the measurement after prolonged storage has been reported previously $[26,27]$.

\section{Clinical data}

Deaths, hospital admissions, ICU admissions and days of hospitalization were recorded by hospital registers, interviewing relatives or the general practitioner, and comparing the 18 months of the study period to a similar period prior to institution of the home care programme (Groups A and B). In Group A, days spent in the hospital when in stable state for HMV training were not taken into account. In Group C, two consecutive periods of 18 months while on LTOT were considered when calculating these parameters.

\section{Statistics}

Data are presented as mean $\pm \mathrm{SD}$. Differences in baseline values were tested by analysis of variance (ANOVA). ANOVA was also applied among groups at the time considered and for the recorded parameters. A p-value of less than 0.05 was considered to be statistically significant.

\section{Results}

Characteristics of patients in the study are shown in table 1. Patients of all groups suffered from a severe airway obstruction with hyperinflation as assessed by reduction in FEV1 and increase in residual (RV). There were no differences between groups in previous duration of LTOT (23 $\pm 6,22 \pm 5$ and $22 \pm 4$ months for patients of Groups A, $\mathrm{B}$ and $\mathrm{C}$, respectively). ABG values on air indicated severe hypoxaemia with hypercapnia. MIP was reduced in all Group A and B patients. No significant differences in ABG values or in dynamic and static volumes were recorded between the three groups at baseline.

During the 18 month follow-up, 4 out of 17 (23\%) Group A patients died, three due to acute respiratory failure (ARF). The other patient died 6 months after the beginning of HMV following a car crash. In group B, 3 out of $17(18 \%)$ patients died due to ARF. In group

Table 2. - Pulmonary function in patients completing the study

\begin{tabular}{|c|c|c|c|c|c|c|c|c|c|c|c|c|}
\hline \multirow[b]{2}{*}{$\begin{array}{l}\text { Month } \\
\text { Subject (n) }\end{array}$} & \multicolumn{4}{|c|}{ Group A } & \multicolumn{4}{|c|}{ Group B } & \multicolumn{4}{|c|}{ Group C } \\
\hline & $\begin{array}{c}0 \\
(17)\end{array}$ & $\begin{array}{c}6 \\
(15)\end{array}$ & $\begin{array}{c}12 \\
(13)\end{array}$ & $\begin{array}{c}18 \\
(13)\end{array}$ & $\begin{array}{c}0 \\
(17)\end{array}$ & $\begin{array}{c}6 \\
(17)\end{array}$ & $\begin{array}{c}12 \\
(16)\end{array}$ & $\begin{array}{c}18 \\
(14)\end{array}$ & $\begin{array}{c}0 \\
(29)\end{array}$ & $\begin{array}{c}6 \\
(28)\end{array}$ & $\begin{array}{c}12 \\
(26)\end{array}$ & $\begin{array}{l}18 \\
(24)\end{array}$ \\
\hline FEV1 $\%$ pred & $31 \pm 10$ & $30 \pm 8$ & $30 \pm 9$ & $31 \pm 12$ & $33 \pm 10$ & $32 \pm 11$ & $29 \pm 10$ & $32 \pm 13$ & $31 \pm 12$ & $32 \pm 8$ & $29 \pm 12$ & $28 \pm 13$ \\
\hline FVC \% pred & $51 \pm 12$ & $52 \pm 11$ & $50 \pm 11$ & $51 \pm 13$ & $54 \pm 13$ & $53 \pm 12$ & $54 \pm 11$ & $54 \pm 12$ & $51 \pm 14$ & $51 \pm 12$ & $48 \pm 13$ & $44 \pm 14 * *$ \\
\hline FEV1/FVC \% & $50 \pm 18$ & $50 \pm 11$ & $49 \pm 14$ & $49 \pm 14$ & $49 \pm 12$ & $50 \pm 9$ & $45 \pm 18$ & $45 \pm 12$ & $50 \pm 18$ & $50 \pm 18$ & $51 \pm 17$ & $49 \pm 15$ \\
\hline MIP $\mathrm{cmH}_{2} \mathrm{O}$ & $50 \pm 4$ & $52 \pm 5$ & $52 \pm 6$ & $56 \pm 7 *$ & $48 \pm 8$ & $47 \pm 9$ & $49 \pm 12$ & $49 \pm 13$ & NA & NA & NA & NA \\
\hline
\end{tabular}

Values are presented as mean \pm SD. For definitions and explanation of groups see legend to table 1. **: $\mathrm{p}<0.005$ (within group $\mathrm{C}$ by analysis of variance (ANOVA)); *: $\mathrm{p}<0.01$ (within group A by ANOVA).

Table 3. - Blood gas analysis levels in patients completing the study

\begin{tabular}{|c|c|c|c|c|c|c|c|c|c|c|c|c|}
\hline \multirow[b]{2}{*}{$\begin{array}{l}\text { Month } \\
\text { Subject }\end{array}$} & \multicolumn{4}{|c|}{ Group A } & \multicolumn{4}{|c|}{ Group B } & \multicolumn{4}{|c|}{ Group C } \\
\hline & $\begin{array}{r}0 \\
(17)\end{array}$ & $\begin{array}{c}6 \\
(15)\end{array}$ & $\begin{array}{c}12 \\
(13)\end{array}$ & $\begin{array}{c}18 \\
(13)\end{array}$ & $\begin{array}{c}0 \\
(17)\end{array}$ & $\begin{array}{c}6 \\
(17)\end{array}$ & $\begin{array}{c}12 \\
(16)\end{array}$ & $\begin{array}{c}18 \\
(14)\end{array}$ & $\begin{array}{c}0 \\
(29)\end{array}$ & $\begin{array}{r}6 \\
(28)\end{array}$ & $\begin{array}{c}12 \\
(26)\end{array}$ & $\begin{array}{c}18 \\
(24)\end{array}$ \\
\hline $\mathrm{pH}^{\dagger}$ & $7.38 \pm 0.03$ & $7.37 \pm 0.02$ & $7.37 \pm 0.01$ & $7.36 \pm 0.02$ & $7.37 \pm 0.01$ & $7.37 \pm 0.01$ & $7.38 \pm 0.01$ & $7.37 \pm 0.01$ & $7.38 \pm 0.03$ & $7.38 \pm 0.01$ & $7.38 \pm 0.02$ & $7.38 \pm 0.02$ \\
\hline $\mathrm{Pa}_{\mathrm{a}} \mathrm{O}_{2} \quad \mathrm{kPa}$ & $6.4 \pm 1.4$ & $6.3 \pm 1.4$ & $6.2 \pm 1.1$ & $6.3 \pm 1.2$ & $6.4 \pm 0.5$ & $6.3 \pm 1.1$ & $6.3 \pm 0.4$ & $6.5 \pm 0.5$ & $6.7 \pm 0.6$ & $6.6 \pm 1.2$ & $6.6 \pm 1.0$ & $6.5 \pm 0.9$ \\
\hline $\mathrm{Pa}_{1}, \mathrm{CO}_{2} \quad \mathrm{kPa}$ & $7.2 \pm 0.9$ & $7.1 \pm 1.2$ & $7.1 \pm 0.8$ & $7.2 \pm 0.9$ & $6.6 \pm 0.6$ & $6.5 \pm 0.8$ & $6.5 \pm 0.5$ & $6.5 \pm 0.5$ & $6.8 \pm 0.6$ & $6.8 \pm 0.9$ & $6.9 \pm 0.6$ & $7.0 \pm 0.6$ \\
\hline
\end{tabular}

$\dagger$ : breathing room air at rest. For definitions and explanation of groups see legend to table 1 . 
Table 4. - Hospital and ICU admissions and days of hospitalization, per patient, before and after beginning the clinical study

\begin{tabular}{|c|c|c|c|c|c|c|c|c|c|}
\hline & \multicolumn{3}{|c|}{ Group A } & \multicolumn{3}{|c|}{ Group B } & \multicolumn{3}{|c|}{ Group C } \\
\hline & Before & p-value & After & Before & p-value & After & Period 1 & p-value & Period 2 \\
\hline Hosp & $2.2 \pm 0.6$ & $<0.005$ & $1.3 \pm 1.1$ & $2.0 \pm 0.7$ & $<0.005$ & $1.0 \pm 0.9$ & $1.5 \pm 0.7$ & NS & $1.5 \pm .11$ \\
\hline ICU admissions & $0.6 \pm 0.6$ & $<0.05$ & $0.2 \pm 0.4$ & $0.3 \pm 0.5$ & NS & $0.2 \pm 0.5$ & $0.2 \pm 0.4$ & NS & $0.4 \pm 0.5$ \\
\hline Days in hospital & $60 \pm 34$ & $<0.005$ & $34 \pm 40$ & $55 \pm 23$ & $<0.005$ & $18 \pm 20$ & $47 \pm 25$ & NS & $38 \pm 29$ \\
\hline
\end{tabular}

For explanation of groups see legend to table 1. ICU: intensive care unit; NS: nonsignificant.

C, 5 out of $29(17 \%)$ patients died due to respiratory causes in the last 18 months. Eighteen month mortality rates in all groups were, therefore, not significantly different.

Tables 2 and 3 show the time-course of lung function and $\mathrm{ABG}$ values. Dynamic flows showed no differences over time in groups undergoing the home care programme. After 18 months, MIP showed a significant increase only in Group A. No change in ABG values was observed in any group.

Differences in the number of hospital admissions, ICU admissions and days of hospital stay due to respiratory illness between 18 months before and following the beginning of the home care programme are shown in table 4 . Institution of the home care programme was followed by a significant reduction in hospital admissions and days of hospital stay in patients from Groups $\mathrm{A}$ and $\mathrm{B}$, while no change in clinical data was observed in the two periods of observation in patients submitted to LTOT alone (Group C). Before institution of the home care programme, ICU admissions were slightly but significantly ( $\mathrm{p}<0.05$, in comparison to other groups) greater in Group A, and a significant reduction was observed over time only in this group.

Percentage of time $(\% t)$ spent in hospital throughout the study is shown in figure $1 . \% t$ significantly decreased

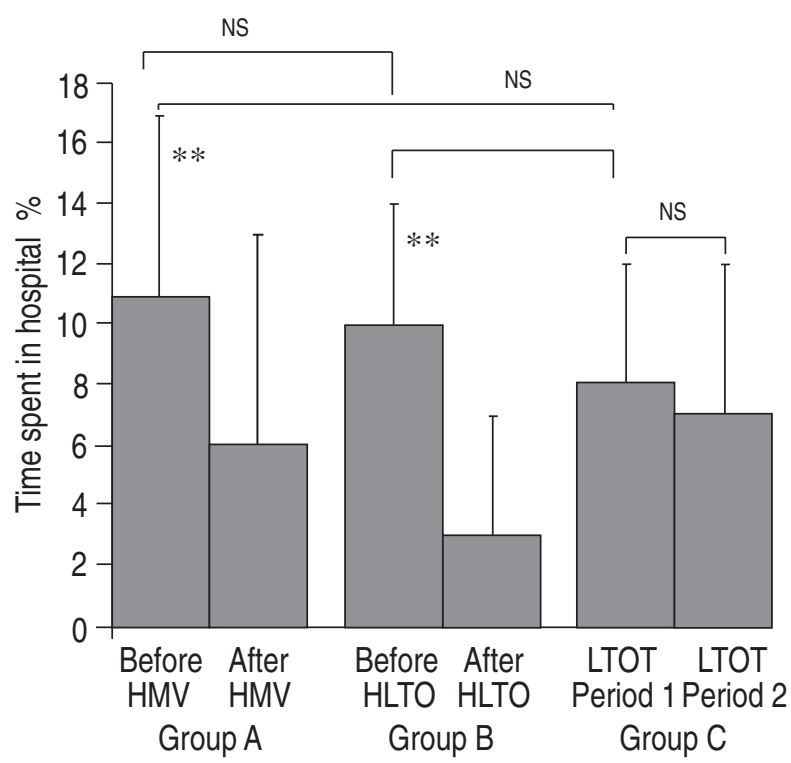

Fig. 1 - Difference in percentage of time spent in hospital before and after beginning the home care programme for Group A and B and between two consecutive periods of long-term oxygen therapy (LTOT) for Group C (Controls). Group A: included in home care programme involving home mechanical ventilation and LTOT (HMV); Group B: included in home care programme involving LTOT only (HLTO); Group C: historical control group performing only LTOT. **: $\mathrm{p}<0.005$, before $v s$ after home care programme. NS: nonsignificant. both in Group A and B after institution of the home care programme HCP. No significant change was observed in the two consecutive observation periods in Group C.

\section{Discussion}

This is a preliminary report of a new programme for home care, integrating long-term treatment for hypercapnic COPD patients. Our study showed that COPD patients undergoing long-term home supervision programmes, including either noninvasive mechanical ventilation and LTOT or LTOT alone, were similarly successful in maintaining stability of lung function and $A B G$ values, and in improving clinical conditions as assessed by reduction in number of respiratory and ICU admissions.

The severity of functional impairment of our COPD patients was shown in this study from the lung function tests performed in the stable state. They suffered from a severe airway obstruction as assessed by a mean FEV1 $<1 \mathrm{~L}$. Stable ABG values showed that the patients of all groups were chronically hypoxaemic and hypercapnic. The role of chronic hypercapnia in the prognosis of COPD patients is still debated. BEGIN [28] considered hypercapnia as a means to avoid overloading of the inspiratory muscles. Hypercapnia per se has not been demonstrated to be associated with a higher mortality risk [29], but the rate of deterioration over time in $\mathrm{Pa}_{\mathrm{a}} \mathrm{CO}_{2}$ was found to be related to the necessity for ICU admission [30]. Similarly, the role of reducing the level of hypercapnia by means of HMV and its generalized use in COPD patients remains controversial.

In our study, no groups showed improvements in $\mathrm{Pa}_{\mathrm{a}} \mathrm{CO}_{2}$, whilst only the Group A patients undergoing home care programme and HMV showed an increase in MIP after 18 months of treatment. In contrast with our study, STRUMPF and co-workers [9] found no improvement in MIP in COPD patients after 3 months of nocturnal treatment with BiPAP®. Their patients were less severely affected than ours (FEV1 $51 \%$ pred) and the duration of their study was too short to appreciate a real effect on a longterm basis. Elliott et al. [31] found no relationship between changes in MIP and changes in $\mathrm{Pa}_{\mathrm{a}} \mathrm{CO}_{2}$ in COPD patients undergoing HMV. A similar period of domiciliary treatment with intermittent negative pressure ventilation (INPV) by means of a poncho-wrap was not able to improve inspiratory muscle strength in less severe COPD patients in the study by SHAPIRO et al. [32]. The difference from these studies might be related to the longer duration of treatment in our study, and might confirm the hypothesis that HMV may improve inspiratory muscle function by resting them [23, 33].

The patients included in the three groups did not differ in terms of baseline anthropometric and functional 
data, while the number of ICU admissions was slightly greater in Group A patients. This clearly depends on patient selection and the criteria of institution of HMV, and may have influenced the results. The value of noninvasive ventilation in patients who have previously used it in exacerbations or who are frequent exacerbators has not been studied; previous studies having recruited stable hypercapnic patients [4, 9-11, 31, 32].

Mortality rate due to respiratory causes was similar in the different groups of patients in our study, suggesting a similar degree of severity in the disease at the time of admission as confirmed by functional measurements. Long-term prognosis of COPD patients surviving an episode of ARF remains controversial [34-39]. CORRADO et al. [39] showed that the overall survival rate during the first year after an episode of ARF treated with an iron-lung was $82 \%$. Patients in their study underwent monthly visits. Comparison of mortality rates between studies is difficult, as the criteria for inclusion of patients, use of mechanical ventilation and medical treatment are different, especially for the oldest studies. As a whole, the prognosis for survival in COPD is considered to be similar for patients experience severe ARF or not, being related to the severity of the underlying disease [40]. Our preliminary data do not justify the generalized use of long-term noninvasive mechanical ventilation in stable hypercapnic COPD. A European long-term prospective, randomized, controlled study is being conducted to evaluate the real benefit of a long-term nasal mask ventilation $v s$ LTOT in patients with severe COPD [41].

The main result in our experience over 18 months was the significant decrease in hospital admissions observed both in Groups A and B in comparison to the time before institution of the home care programme, whilst Group $\mathrm{C}$ patients showed a stable trend in days spent in hospital during the two consecutive 18 month periods evaluated (fig. 1). ICU admission significantly decreased only in Group A. This could be partly due to the difference in ICU admissions prior to the study. These findings in the two groups appear to be possibly related to the home care programme per se independent of whether or not long-term ventilatory support was given in addition to oxygen therapy. LEGER et al. [11] in their uncontrolled study also recorded a significant reduction in number of hospitalizations in mechanically-ventilated COPD patients over 3 yrs, but their patients also underwent a home supervision programme.

Reduction in hospital stay for COPD is consistent with cost-savings $[3,11]$, but is not necessarily related to the necessity for MV [13]. Analysis of costs has not been directly taken into account in our study. However, precise indications of costs-savings are difficult to draw as they are influenced by many factors besides hospitalization. In fact, differences in the design of the home care programme proposed and the selection of patients may explain different results $[12,13]$.

Our study had definite limitations. Historical comparison of different treatments must be interpreted with caution because treatment strategies may change with time and such studies are considered to favour the treatment group (Groups A and B) [42]. Furthermore, the retrospective analysis of data may be criticized, e.g. it limits further information, especially on some circumstances of the follow-up (e.g. quality of life or cost of treatment).
Groups A and B were also limited to those who could tolerate the technique. Nevertheless, a retrospective study gives information on a "real" operational setting.

In conclusion, our controlled study suggests that there is a reduction of hospital admission, within 18 months, for chronic obstructive pulmonary disease patients undergoing home supervision programmes with long-term oxygen therapy both alone and combined with long-term home mechanical ventilation.

\section{References}

1. Report of British Research Medical Council Working Party. Long-term domiciliary oxygen therapy in chronic hypoxic cor pulmonale complicating chronic bronchitis and emphysema. Lancet 1981; i: 681-686.

2. Nocturnal Oxygen Therapy Trial Group. Continuous or nocturnal oxygen therapy in hypoxaemic COLD. Ann Intern Med 1980; 93: 391-398.

3. Gilmartin ME. Long-term mechanical ventilation outside the hospital. In: Pierson DJ, Kacmareck B, eds. Foundations of Respiratory Care. Edimburgh, ChurchillLivingstone, 1992; pp. 1185-1204.

4. Garay SM, Turino GM, Goldring RM. Sustained reversal of chronic hypercapnia in patients with alveolar hypoventilation syndromes: long-term maintenance with noninvasive mechanical ventilation. Am J Med 1981; 70: 269-274.

5. Curran FJ. Night ventilation by body respirator for patients in chronic respiratory failure due to late stage Duchenne muscular dystrophy. Arch Phys Med Rehabil 1981; 62: 270-274.

6. Ellis ER, Bye PTP, Bruderer JW, Sullivan CE. Treatment of respiratory failure during sleep in patients with neuromuscular disease: positive-pressure ventilation through a nose mask. Am Rev Respir Dis 1987; 135: 144-152.

7. Ellis ER, Grunstein RR, Chan S, Bye PTP, Sullivan CE. Noninvasive ventilatory support during sleep improves respiratory failure in kyphoscoliosis. Chest 1988; 94 : 811-815.

8. Hill NS, Eveloff SE, Carlisle CC, Goff SG. Efficacy of nocturnal nasal ventilation in patients with restrictive thoracic diseases. Am Rev Respir Dis 1992; 145: 365-371.

9. Strumpf DA, Millman RP, Carlisle CC, et al. Nocturnal positive pressure ventilation via nasal mask in patients with severe chronic obstructive pulmonary disease. Am Rev Respir Dis 1991; 144: 1234-1239.

10. Elliott MW, Simonds AK, Carroll MP, Wedzicha JA, Branthwaite MA. Domiciliary nocturnal nasal intermittent positive pressure ventilation in hypercapnic respiratory failure due to chronic obstructive lung disease: effects on steep and quality of life. Thorax 1992; 47: 342-348.

11. Leger P, Bedicam JM, Cornette A, et al. Nasal intermittent positive pressure ventilation: long-term follow-up in patients with severe chronic respiratory insufficiency. Chest 1994; 105: 100-105.

12. Roselle S, D'Amico S. The effect of home respiratory therapy on hospital readmission rates of patients with chronic obstructive pulmonary disease. Respir Care 1982; 27: 1194-1199.

13. Bergner M, Hudson LP, Conrad DA, et al. The cost and efficacy of home care for patients with chronic lung disease. Med Care 1988; 26: 566-579.

14. Plummer Al, O'Donohue WJ, Petty TL. Consensus conference on problems in home mechanical ventilation. Am Rev Respir Dis 1989; 140: 555-560. 
15. Campbell-Haggerty M, Stockdale-Wooley R, Nair S. Respi-care: an innovative home care program for the patient with chronic obstructive pulmonary disease. Chest 1991; 100: 607-612.

16. Goldberg AJ. Technology assessment and support of life-sustaining devices in home care: the home care physician perspective. Chest 1994; 105: 1448-1453.

17. Amencan Thoracic Society. Standards for the diagnosis and care of patients with chronic obstructive pulmonary disease (COPD) and asthma. Am Rev Respir Dis 1987; 136: 225-243.

18. European Society of Pneumology Task Group. Recommendations for long-term oxygen therapy (LTOT). Eur Respir J 1989; 2: 160-164.

19. Gyulay S, Olson LG, Hensley MT, et al. A comparison of clinical assessment and home oximetry in the diagnosis of obstructive sleep apnea. Am Rev Respir Dis 1993; 147; 50-53.

20. Vitaeca M, Rubini F, Foglio K, Scalvini S, Nava S, Ambrosino N. Noninvasive modalities of positive pressure ventilation improve the outcome of acute exacerbations in COLD patients. Intensive Care Med 1993; 10: 450-455.

21. Wijkstra PJ, Van Altena R, Kraan J, Otten V, Postma TS, Koeter GH. Quality of life in patients with chronic obstructive pulmonary diseases improves after rehabilitation at home. Eur Respir J 1994; 7: 269-273.

22. Strumpf DA, Carlisle CC, Millman RP, Smith KW, Hill NS. An evaluation of the Respironics BiPAP bilevel CPAP device for delivery of assisted ventilation. Respir Care 1990; 35: 415-422.

23. Ambrosino N, Nava S, Bertone P, Fracchia C, Rampulla C. Physiologic evaluation of pressure support ventilation by nasal mask in patients with stable COPD. Chest 1992; 101: 385-391.

24. Black LF, Hyatt RE. Maximal respiratory pressures: normal values and relationship to age and sex. Am Rev Respir Dis 1969; 99: 696-702.

25. Bruschi C, Cerveri I, Zoia MC, et al. Reference values of maximal respiratory mouth pressures: a populationbased study. Am Rev Respir Dis 1992; 146: 790-793

26. Siggsard-Andersen O. Sampling and storing of blood for determination of acid-base status. Scand J Clin Lab Invest 1961; 13: 195-204.

27. Haskins SCD. Sampling and storage of blood for $\mathrm{pH}$ and blood gases analysis. JAMA 1977; 170: 429-433.

28. Begin P, Grassino A. Inspiratory muscle dysfunction and chronic hypercapnia in chronic obstructive pulmonary disease. Am Rev Respir Dis 1991; 143: 905-912.
29. Dubois P, Jamart J, Machiels J, Smeets F, Lulling J. Prognosis of severely hypoxemic patients receiving longterm oxygen therapy. Chest 1994; 105: 469-474.

30. Vitacca M, Foglio K, Scalvini S, Marangoni S, Quadri A, Ambrosino N. Time course of pulmonary function before admission into ICU. Chest 1992; 102: $1737-$ 1741.

31. Elliott MW, Mulvey DA, Moxham J, Green M, Branthwaite MA. Domiciliary nocturnal nasal intermittent positive pressure ventilation in COPD: mechanisms underlying changes in arterial blood gas tensions. Eur Respir $J$ 1991; 4: 1044-1052.

32. Shapiro SH, Ernst P, Gray-Donald K, et al. Effect of negative pressure ventilation in severe chronic obstructive pulmonary disease. Lancet 1992; 340: 1425-1429.

33. Carrey Z, Gottfried SB, Levy RD. Ventilatory muscle support in respiratory failure with nasal positive pressure ventilation. Chest 1990; 97: 150-158.

34. Moser KM, Shebel GM, Beamon AJ. Acute respiratory failure in patients with chronic obstructive pulmonary disease: long-term survival after treatment in an intensive care unit. JAMA 1973; 225: 705-707.

35. Martin TR, Lewis SW, Albert RK. The prognosis of patients with COPD after hospitalization for acute respiratory failure. Chest 1982; 82: 310-314.

36. Gracey DR, Naessens JM, Krishan I, Marsh HM. Hospital and post-hospital survival in patients mechanically-ventilated for more than 29 days. Chest 1992; 101: 211-214.

37. Stauffer JL, Fayter N, Graves B, Cromb M, Lynch JC, Goebel P. Survival following mechanical ventilation for acute respiratory failure in adult men. Chest 1993; 104: 1222-1229.

38. Nava S, Rubini F, Zanotti E, et al. Survival and prediction of successful ventilator weaning in COPD patients requiring mechanical ventilation for more than 21 days. Eur Respir J 1994; 7: 1645-1652.

39. Corrado A, Bruscoli G, Messori A, et al. Iron-lung treatment of subjects with COPD in acute respiratory failure: evaluation of short- and long-term prognosis. Chest 1992; 101: 692-696.

40. Muir JF. Home mechanical ventilation. Thorax 1993; 48: 1264-1273.

41. Morgan MDL. Conference report. Second International Conference on advances in pulmonary rehabilitation and management of chronic respiratory failure. Venice, November 1992. Thorax 1993; 48: 296-297.

42. Sacks H, Chalmers TC, Smith H Jr. Randomized versus historical controls for clinical trials. Am J Med 1982; 72: 233-240. 